Southern Counties Eye and Ear Hospital and ophthalmic surgeon to the Royal West Sussex Hospital, Chichester. He began his ophthalmic life as clinical assistant to the Royal Victoria Eye and Ear Hospital, Dublin. A few years ago he took into partnership Nigel Cridland, son of the well known Secretary and Master of the Oxford Congress. At the outbreak of war Cridland joined the forces and Valentine was obliged to resume extended duties and was in full activity till a few hours before his death, which took place on March 27. He took a great interest in the Portsmouth and Southsea Rotary Club, and was a keen Freemason.

Valentine was an enthusiastic yachtsman, and was ViceCommodore of the Portsmouth Sailing Club, and Rear-Commodore of the Royal Portsmouth Corinthian Yacht Club. Nowhere was he happier than in his small yacht surrounded by one or more members of his family and their friends. It seems but yesterday when I saw his small yacht sailing into Yarmouth, Isle-of-Wight, and had a chat with him on that most fascinating of all sports, small boat sailing. During his whole professional career he was ably supported by his wife, herself the daughter of a well known Dublin medical teacher, Professor Walter Smith. She was a frequent visitor at the Oxford Congress. He is survived by two daughters, one an officer in the W.A.A.F., and the other in the V.A.D. His only son died at Sherborne School. Our sympathy goes out to them all. They have lost a devoted father, and many of us a dear friend. Valentine was deeply moved by the recent developments in the outlook of the medical profession, and especially in the future of ophthalmic surgery. He did not see eye to eye with the British Medical Association, holding quite rightly as many of us think, that no patient in these days should be seen for the reduced fees recommended by the Group Committee. He maintained his views actively and with his characteristic courage.'

\title{
GEORGE LINDSAY JOHNSON
}

THE death of G. Lindsay Johnson at Durban, Natal, on August 1, 1943, was noted in our December number.

Through the kindness of the Council of the Royal College of Surgeons and of Mr. Le Fanu, Librarian, we are now able to give some details of his career.

Johnson was born at Manchester in 1853. Much of his education was taken in Germany, and he was in Strasbourg when the Prussians seized it in 1870. After a year on a ranch in Australia, where he had relatives, he studied at Owen's College, Manchester, and at Gottingen, Caius College, Cambridge, and St. Bartholomew's Hospital. He took the M.D.Cantab. in 1890 and the F.R.C.S. in 1884 .

His ophthalmic career started when he acted as Registrar at the Royal Westminster Ophthalmic Hospital, and later he worked at the 
Royal Eye Hospital with Brudenell Carter. Much of his spare time time in early years was spent at the Zoo where he studied the com? parative anatomy of the eye. Papers on the mammalian eyes appeared in the Phil. Trans: Roy. Soc. Lond. in 1901, and on reptilian and amphibian eyes in 1924. He was a pioneer in colour photography and maintained his interest in photography to the end of his life.

Johnson left England for South Africa in 1911 and practised for a. time in Johannesburg. He was a good linguist and an extremely versatile man. In,later years he took great interest in spiritualism and devoted much of his time to devising optical instruments and photographic experiments. He wrote a good deal. . Besides those Royal Society papers already mentioned, his best known ophthalmic book was a very convenient pocket atlas of the fundus in which he had the advantage of Mr. Head's collaboration in the illustrations. This book went to a second edition.

\section{NORMAN HOWARD PIKE}

Norman Howard Pike, of 6, Charlton Park Gate, Cheltenham, died after a short illness on March 12, at the age of 71. He was one of a family of eleven and was educated at Dulwich College. At Guy's he was contemporary with a galaxy of talen't, obtäined Honours in medicine and obstetrics in the London M.B., B.S., and in 1896 was appointed Resident Obstetrical Assistant. The following year he acted as House Physician to Dr. Hale White.

$\mathrm{He}$ worked in general practice at Heckmondwike (Yorks.) for ten years before specializing in ophthalmology and oto-laryngology. It was in 1907 that he left his practice and, accompanied by his wife and children, went to study in Vienna. It is greatly to his credit that during this period of tuition there, he contrived a useful piece of clinical research, the results of which appeared in the November and December numbers of the Journal of Laryngology, Rhinology and Otology in 1908 under the title "An Examination into the Condition of the Vestibular Apparatus in a Series of Cases of Deafness of Non-suppurative Origin." "Thirty-eight of the seventy-four cases reported on he investigated himself whilst working in Professor Urbantschitsch's clinic. The remainder he owed to the collaboration. of Dr. Bárány. An important and interesting point which emerged was the constant finding of diminution or absence of vestibular irritability in cases of deaf congenital syphilitics. On his return to England, he worked as a Clinical Assistant at Moorfields and as a House Surgeon at the Royal Ear Hospital, Soho, prior to his appointment in 1909 as Surgeon to the Eye, Ear, Nose and Throat Hospital at Cheltenham, before its amalgamation with the General Hospital. Until his retirement in 1932 under the age limit regulations he served the hospital efficiently 